\title{
Hepatitis B Variants: Are Canadians Protected?
}

\author{
Fiona G. Kouyoumdjian
}

Abstract: Hepatitis B virus is common in Canada and is associated with major clinical sequelae. Measures such as vaccination and detection programs have been widely implemented as means of mitigating the impact of HBV on individuals and on the public's health. For over a decade, mutant strains of HBV have been reported in countries throughout the world, with the notable exception of Canada. If certain mutant strains of HBV developed in or were spread to Canada, our existing vaccination and detection programs might not effectively protect Canadians.

\section{Author Correspondence: fkouyoum@dal.ca}

$\mathrm{H}$

epatitis B is a virus that affects a significant number of people, with an estimated 35 million carriers worldwide.' Within Canada, the annually reported incidence of clinically recognized acute hepatitis B virus (HBV) is 2.3 per 100,000 . However, this is likely an underestimate of the rate of infection, since $\mathrm{HBV}$ is asymptomatic in $90 \%$ of infants and young children and in $50 \%$ of adolescents and adults. ${ }^{2}$ The prevalence of HBVinfected individuals in Canada is estimated to be $2 \%$, with $5 \%$ to $10 \%$ having serological evidence of previous $\mathrm{HBV}$ infection. ${ }^{3}$ Prevalence varies significantly, however, between populations within Canada; the prevalence of $\mathrm{HBV}$ surface antigen ( $\mathrm{Hbs} \mathrm{Ag}$ ), an indicator of infection with $\mathrm{HBV}$, is high in immigrant populations $(7.4 \%)$ and the Inuit $(6.9 \%)$, and intermediate among First Nations populations $(0.3 \%)$, adolescents $(0.4 \%)$, STD clinic visitors $(0.3 \%)$ and residents of long-term care facilities $(0.6 \%){ }^{2}$

$\mathrm{HBV}$ is transmissible via several routes. Infection occurs percutaneously through injection drug use or through exposure to contaminated blood or body fluids, sexually, vertically, and horizontally between children and household contacts through skin lesions or sharing of bloodcontaminated toothbrushes or razors. ${ }^{2}$ Infection with HBV causes a variety of acute and chronic liver diseases including fatal fulminant hepatitis, cirrhosis and hepatocellular carcinoma, ${ }^{1}$ all of which are associated with high morbidity and mortality.

\section{Prevention and Control of Hepatitis $B$ infection}

A key component of the public health effort to decrease the burden of $\mathrm{HBV}$ in Canada is primary prevention through vaccination. A vaccine for hepatitis $B$ has been available since 1982, when hepatitis B surface antigen (HBsAg) was taken from the plasma of people infected with $\mathrm{HBV}$, and purified and processed to ensure that the HBV and any other viruses in the plasma were inactivated. ${ }^{4}$ In the mid-1980s, a recombinant vaccine became available, ${ }^{4}$ which is produced using bioengineered yeast Saccharomyces cerevisiae. Ninety percent of patients younger than 45 or 50 years of age have high antibody titres after three doses of the vaccine. ${ }^{5}$ The plasma-derived vaccine has not been available in Canada since the early 1990s, and recombinant vaccines are used in vaccinations programs."

In Canada, vaccination is recommended for all individuals "at increased risk, such as homosexual/bisexual men [presumably who practice unsafe sex], persons with a recent history of STDs or multiple sexual partners, injection drug users, inmates of correctional facilities, household and sexual contacts of HBV-infected persons, and health care and emergency services workers." ${ }^{2}$ Also, since the early 1990 s, a universal hepatitis B vaccination program has been implemented across Canada, targeting pre-adolescents aged 9 to 13. This program fails, however, to protect children from infection in infancy and early childhood, which accounts for $10-15 \%$ of all chronic hepatitis B cases.

Another important public health program in Canada is the universal screening of pregnant women for $\mathrm{HBsAg}$ during prenatal visits or at the time of delivery. For an infant of a HBsAg positive mother, administering hepatitis B immunoglobulin (passive immunization) within 48 hours after birth and a course of three doses of hepatitis $B$ vaccine (active immunization) within 6 months after birth, reduces the risk of vertical transmission by more than $90 \%$

Other public health measures include strategies to reduce nosocomial infection with $\mathrm{HBV}$, and notification of cases of HBV infection through the National Notifiable Disease Reporting System. ${ }^{2}$ Notification allows tracking of the incidence of $\mathrm{HBV}$, as well as tracing and notification of appropriate sexual or household contacts and the administration of hepatitis B immunoglobulin and hepatitis $B$ vaccine.

\section{Structure of $\mathrm{HBV}$}

Hepatitis B virus is a double-stranded DNA virus, which replicates by a process that involves reverse transcription through an RNA intermediate. The HBV genome is $3.2 \mathrm{~kb}$, and is enveloped in a spheric virion that is composed of an outer envelope and an inner nucleocapsid. The genome contains four overlapping open reading frames (ORFs) encoding HBV DNA polymerase, surface antigen (HBsAg), core protein and $\mathrm{HBX}$, respectively. That the structure of $\mathrm{HBV}$ is compact and overlapping implies that a mutation at any single point may affect the structure and function of more than one protein. ${ }^{8}$

The HBV viral envelope is composed of cellular lipids and three related proteins: the large surface antigen, the middle surface antigen, and the small surface antigen (or HBsAg), all of which share a common carboxy-terminal 


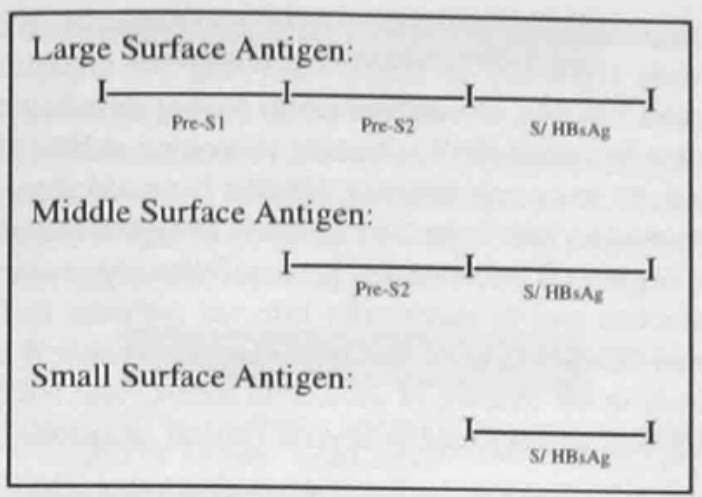

Figure 1: Hepatitis B Virus Surface Antigens

end: the $\mathrm{S}$ segment, or $\mathrm{HBs} \mathrm{Ag}$, as illustrated in Figure 1. ${ }^{9}$ The HBsAg region spans amino acids 100 to 160 , and all subtypes of HBV share a common region within the HBsAg segment, termed the $a$ determinant, which spans amino acids 124147 and is postulated to form a double loop structure. ${ }^{10}$ Antibodies against the $a$ determinant, whether as a result of effective vaccination or acute hepatitis B infection, confer protection against all nine HBV subtypes. ${ }^{10}$

The protein coded for by the HBsAg region, that is, the $\mathrm{HBsAg}$, is commonly administered in a recombinant form as a vaccine, and people who are successfully vaccinated against HBV definitively develop an antibody response against the HBsAg protein. Most commonly, this antibody response develops predominantly against the highly antigenic region coded for by the $a$ determinant. ${ }^{8}$ It is easy to imagine, therefore, that a virus with a mutation in this area of the HBsAg might not be recognized by antibodies induced through vaccination.

\section{Emergence of Mutant Strains of $\mathrm{HBV}$}

In 1988, the emergence of a variant of $\mathrm{HBV}$ was suggested by the findings of hepatitis $\mathrm{B}$ infection in individuals who had been successfully immunized, that is, who were positive for anti-HBsAg antibodies."

To date, viral strains with mutations in each of the four ORFs of HBV have been detected. Mutations vary in their clinical significance, with characteristics common to mutations in certain regions: enveloped protein mutations are associated with evasion of host immunologic surveillance; pre-core, core promoter and core region mutations are associated with increased disease severity; DNA polymerase mutations are associated with resistance to antiviral agents; and $\mathrm{X}$ region mutations are associated with hepatocellular carcinogenesis. ${ }^{12}$ Various HBsAg mutations have now been identified in many areas of the world, including Taiwan, China, Japan, Hong Kong, Singapore, Thailand, India, Germany, the United Kingdom, the USA, Brazil, and West Africa.

The HBV polymerase has a mutation rate of about 2-10 base substitutions per site per year. ${ }^{13}$ Both this high mutation rate and the fact that certain mutations would confer survival over wild-type HBV make proliferation of hepatitis $B$ virus mutants favourable. The spread of mutants is affected by factors such as the specific characteristics of the mutants described above, as well as public health measures implemented to prevent and control the spread of mutant viruses, which would conceivably be similar to those utilized for hepatitis B virus in general.

The epidemiology of HBV variants is largely unknown. A random population survey of 2001 people in Singapore between 1990 and 1992 revealed a prevalence of $0.8 \%$ of carriers of $\mathrm{HBV}$ variants. ${ }^{14}$ Factors such as high maternal viral loads and mutations occurring elsewhere in the mother's HBV S gene (i.e. coding for $\mathrm{HBs} \mathrm{Ag}$ ) are associated with an increased risk of $\mathrm{HBsAg}$ mutations occurring in offspring. ${ }^{15} \mathrm{HBsAg}$ mutants have also developed in liver transplant recipients receiving hepatitis B immunoglobulin and less frequently, spontaneously during the course of a chronic HBV infection. ${ }^{12}$

\section{Public Health Concerns}

Mutations in the region coding for $\mathrm{HBsAg}$ are of major clinical and public health concern, since effective immunization and detection are predicated on the immune response to, and recognition of this region, respectively. In assessing the significance of these mutants in Canada and elsewhere, certain key parameters must be investigated and defined:

a. Are HBV mutants of clinical significance?

b. Do hepatitis B surface antigen vaccination and hepatitis B immunoglobulin confer protection against infection with mutant $\mathrm{HBV}$ ?

c. Is infection with mutant $\mathrm{HBV}$ detectable with existing tests?

Given the huge scale of programs in Canada to prevent and control the spread of HBV, such as universal adolescent vaccination and universal screening of pregnant women, and efforts to decrease nosocomial infection, HBV is clearly appreciated as a significant threat to public health. HBV mutant strains are associated with the same sequelae as wild type strains, including, as listed above, fatal fulminant hepatitis, cirrhosis, and hepatocellular carcinoma. ${ }^{8}$ Thus it must be a priority of the medical and public health communities to curb the spread of hepatitis B virus, in both wild type and mutant form.

A second key issue is determining whether the traditional means of protection against infection with $\mathrm{HBV}$ (hepatitis B immunoglobulin and the hepatitis B vaccine), confer protection against infection with mutant HBV strains. In 1990, a mutation in the HBsAg was described in an Italian child who acquired HBV despite the appropriate administration of vaccination and hepatitis B immunoglobulin at birth. ${ }^{16}$ In a large study in Singapore of 345 infants born to mothers with $\mathrm{HBs} A \mathrm{~g}$ and $\mathrm{HBV} e$ antigen (the protein product of the precore and core regions of the virus), hepatitis immunoglobulin was administered at birth and hepatitis B vaccine doses of $5 \mu \mathrm{g}$ or $10 \mu \mathrm{g}$ were administered within 24 hours of birth, then 1 month and 2 months later.

In this group, there were 41 breakthroughs of infection 
with $\mathrm{HBV}$ despite the presence of anti-HBsAg antibodies. Control groups of 670 children born to mothers with $\mathrm{HBsAg}$ and anti- $e$ antigen and similarly immunized, as well as 108 children born to mothers without $\mathrm{HBsAg}$ given the vaccine alone, revealed no infection. These findings demonstrate that hepatitis B immunoglobulin and vaccine fail to protect against at least some strains of $\mathrm{HBV}$.

A third key issue is whether HBsAg mutant viruses are detectable by conventional means. If a mutant were not detectable, then hepatitis B could contaminate the blood supply and be transmitted through the use of blood products. Furthermore, it would take longer to diagnose patients infected with hepatitis B virus, such that their medical treatment and appropriate prophylaxis for their personal contacts would be delayed, which would worsen the burden of the disease on the individual and increase the spread of $\mathrm{HBV}$ in the population.

Typically, hepatitis B infection is diagnosed on the basis of the presence of $\mathrm{HBsAg}$ in the serum, and immunity is assessed by the detection of anti-HBsAg antibodies in the serum. In 1995, an Indonesian patient was reported to have developed clinically significant hepatitis B infection, ${ }^{17}$ which was later demonstrated to be a mutant form of the virus. The strain of hepatitis B with which he was infected had the following characteristics:

a. Undetectable by a monoclonal-antibody-based ELISA (Auszyme, from Abbott Laboratories)

b. Polyclonal-antibody-based radioimmunoassay (Ausria II, produced by Abbott Laboratories) was strongly immunoreactive

c. Positive for anti-HBc, Hbe antigen, and HBV DNA by dot-blot hybridization

d. Negative for anti-HBs, IgM anti-HBc, markers for delta virus, and HCV RNA (by nested reverse transcriptase $\mathrm{PCR}$ )

To get a broader understanding of the detection of hepatitis B mutants with mutations in the $\mathrm{HBs} A g$ region, a private company constructed mutants based on the sequences of mutants reported in the literature, then evaluated detection of the mutants using existing assays..$^{18}$ Nine assays (six of the company's immunoassays and three commercially available $\mathrm{HBsAg}$ assays) were evaluated in their ability to detect twenty mutations reported in the literature. These experiments revealed that all of the company's immunoassays but none of the commercial assays detected the existence of the most prevalent $\mathrm{HBsAg}$ variant: a glycine to arginine substitution at amino acid 145. Only one test detected all the mutations assayed, and all the others detected some but not all mutant hepatitis B viruses. The study did not include discussion of the costs of the various assays, making it difficult to assess the feasibility of using such detection methods on a large scale.

Another approach to avoid the difficulties in detection of mutated $\mathrm{HBsAg}$ is to look for serum markers of infection other than $\mathrm{HBsAg}$, an approach which is currently being used in some hospitals in Canada. In 2001, an argument and algorithm were presented for the use of hepatitis $\mathrm{B}$ core antibody $(\mathrm{HBCAb})$ in initial screening for hepatitis B infection. ${ }^{5}$ In fact, the authors report having switched their protocol for initial HBV screening to looking at HBcAb in order to be more cost efficient. HBcAb is a good choice of serum marker, as it is the first antibody to appear following acute hepatitis $\mathrm{B}$ infection and persists following resolution of infection and in chronically infected patients. In fact, isolated $\mathrm{HBcAb}$ (that is, the presence of hepatitis B core antibody in the absence of detectable $\mathrm{HBsAg}$ and $\mathrm{HBsAb}$ ) is common, and is found in several clinical situations: ${ }^{5}$

i) During the "serum window" period between the disappearance of $\mathrm{HBs} \mathrm{Ag}$ and the appearance of $\mathrm{HBsAb}$

ii) A remote resolved infection with the decline of $\mathrm{HBsAb}$ to undetectable levels

iii) Ongoing chronic infection with $\mathrm{HBsAg}$ that escapes detection because of low levels of $\mathrm{HBsAg}$ or due to the presence of a mutation rendering the HBsAg undetectable using certain diagnostic assays

These data suggest that commercially available assays are not consistently successful in identifying $\mathrm{HBs} A g$ mutants, and that other diagnostic tests can effectively identify hepatitis B virus, whether wild type or mutant strain. Of course, in assessing which test should be used to detect hepatitis B virus, information about costs must be balanced with an appreciation of the magnitude of the threat to public health of hepatitis B virus and of new mutants.

\section{CONClusion}

In a 1994 article, it was recommended that "urgent consideration... be given to the introduction of routine screening by nucleic acid based technology of blood donors and tissue and organ donors" and that "consideration... be given to [the incorporation] into current hepatitis B vaccines of antigenic components which will confer protection against infection by the predominant mutant(s)..."13 Nine years later, little headway seems to have been made in the implementation of these recommendations.

Neither existing anecdotal nor epidemiological evidence suggests the existence in Canada of hepatitis B mutants with mutations in the $\mathrm{HBsAg}$ region, which are not detectable by conventional means or against which the vaccine is not protective. That being said, in the case of an infection with such a hepatitis B mutant, whether arising de novo or acquired abroad, the existing structure of detection and vaccination would fail to protect people in Canada from its spread. For this reason, it is important to assess and enhance the procedures in place to prevent and control the spread of hepatitis B virus, and to ensure that they will function well in the event of the arrival of hepatitis B mutants to Canada. 


\section{ACKNOWLEDGMENTS}

An earlier version of this article was written in association with a placement at the Nova Scotia Department of Health as part of the Med II Population Health course. Thank you to Juanita MacPhee and Dr. Strang in the Department of Health, and to Dr. Scott Halperin.

\section{REFERENCES}

1. Chen WN, Oon CJ. Human hepatitis B virus mutants: significance of molecular changes. EEBS Letters 1999; 453: 237-242.

2. Zhang J, Zou S, Giulivi A. Hepatitis B in Canada. Viral Hepatitis and Emerging Bloodborne Pathogens in Canada 2001: 27: S3. Retrieved January 26th, 2003 from http://www.hc-sc.gc.ca/ pphb-dgspsp/publicat/ccdr-rmtc/0Ivol27/27s3/27s3e_e.html.

3. Minuk GY, Uhanova J. Chronic Hepatitis B in Canada. Canadian Journal of Infectious Diseases 2001: 12(6): 351-356.

4. WHO Department of Communicable Disease Surveillance and Response. Hepatitis B. http://www.who.int/emc-documents/ hepatitis/docs/whocdscsrlyo20022/surveillance/vaccines.html.

5. Al-Mekhaizeem KA, Miriello M, Sherker AH. The frequency and significance of isolated hepatitis B core antibody and the suggested management of patients. Canadian Medical Association Journal 2001; 165 (8): 1063-1064.

6. Health Canada. Canadian Immunization Guide, $6^{\text {th }}$ Ed. 2002.

7. Eleftheriou A, Kalakoutis G, Pavlides N. Transfusion transmitted viruses in pregnancy. Journal of Pediatric Endocrinology and Metabolism 1998; 11: 901-914.

8. Chen WN, Oon CJ. Hepatitis B Virus Mutants: An Overview. Journal of Gastroenterology and Hepatology 2002; 17: S497S499

9. Carman WF, Korula J, Wallace L, MacPhee R, Mimms L, Decker R. Fulminant reactivation of hepatitis $B$ due to envelope protein mutant that escaped detection by monoclonal HBsAg ELISA. Lancet 1995; 345: 1406-1407

10. Weber B, Dengler T, Berger A, Doerr HW, Rabenau H Evaluation of Two New Automated Assays for Hepatitis B Virus
Surface Antigen (HBsAg) Detection: IMMULITE HBsAg and IMMULITE $2000 \mathrm{HBsAg}$. Journal of Clinical Microbiology 2003; 4 I(1): 135-143.

11. Zanetti AR, Tanzi E, Manzillo G, Maio G, Shreglia C, Caporaso N, Thomas H, Zuckerman AJ. Hepatitis B variant in Europe. Lancet 1988; 2: 1132-1133.

12. Minuk GY, Giulivi A. Hepatitis B Mutants and Their Relevance to the Health Care System. Viral Hepatitis and Emerging Bloodborne Pathogens in Canada 2001; 27: S3. Retrieved May $5^{\text {th }}, 2003$ from http://www.hc-sc.gc.ca/pphb-dgspsp/publical ccdr-rmtc/01vol 27/27s3/27s3j_e.html.

13. Zuckerman AJ, Zuckerman JN. Molecular Epidemiology of Hepatitis B Virus Mutants. Journal of Medical Virology 1999; 58: 193-195.

14. Oon CJ, Tan KL, Harrison T, Zuckerman AJ. Natural history of hepatitis B surface antigen mutants in children. Lancet 1996 348: 1524

15. Carman WF. The clinical significance of surface antigen variants of hepatitis B virus. Journal of Viral Hepatology 1997; 4: 1120

16. Carman WF, Zanetti AR, Karayiannis P. Vaccine-induced escape mutant of hepatitis B virus. Lancet 1990; 335: 325-329.

17. Carman WF, Korula J, Wallace L, MacPhee R, Mimms L, Decker R. Fulminant reactivation of hepatitis B due to envelope protein mutant that escaped detection by monoclonal HBsAg ELISA. Lancer 1995; 345: 1406-1407.

18. Coleman PF, Chen YCJ, Mushahwar IK. Immunoassay Detection of Hepatitis B Surface Antigen Mutants. Journal of Medical Virology 1999; 59: 19-24.

\section{ABOUT THEAUTHOR}

Fiona Kouyoumdjian is a third year medical student at Dalhousie University. She has a Bachelor of Arts with Honours in History and Biology from Brown University. She has recently completed a Masters in Public Health at Johns Hopkins University, with a focus in International Health and a certificate in Health and Human Rights. 